\title{
The intake of fried virgin olive or sunflower oils differentially induces oxidative stress in rat liver microsomes
}

\author{
José L. Quiles ${ }^{1}$, Jesús R. Huertas ${ }^{1}$, Maurizio Battino ${ }^{2}$, M. Carmen Ramírez-Tortosa ${ }^{3}$, \\ Modesta Cassinello $^{1}$, José Mataix ${ }^{1}$, Magdalena Lopez-Frias ${ }^{1}$ and Mariano Mañas ${ }^{1}$ \\ ${ }^{1}$ Institute of Nutrition and Food Technology, Dept of Physiology, University of Granada, Granada, Spain \\ ${ }^{2}$ Institute of Biochemistry, Faculty of Medicine, University of Ancona, Ancona, Italy \\ ${ }^{3}$ Institute of Nutrition and Food Technology, Dept of Biochemistry and Molecular Biology, University of Granada, \\ Granada, Spain
}

(Received 7 September 2001 - Revised 25 January 2002 - Accepted 19 February 2002)

\begin{abstract}
The effects of non-fried and fried virgin olive and sunflower oils on rat liver microsomal compositional features have been investigated. In addition, plasma antioxidants ( $\alpha$-tocopherol and ubiquinone 9) were investigated as well as the possible oxidative modifications suffered by virgin olive and sunflower oils during the frying process. The frying process decreased the content of $\alpha$-tocopherol and phenolics in the oils and increased total polar materials. Sunflower oil was affected to a greater extent than olive oil. In rats, the intake of fried oil led to higher levels of lipid peroxidation and a lower concentration of plasma antioxidants. Microsomal fatty acid and antioxidant profiles were also altered. It seems that a strong relationship exists between the loss of antioxidants and the production of toxic compounds in the oils after frying and the extent of the peroxidative events in microsomes, which were also different depending on the fat source. The highly unsaturated sunflower oil was less resistant to the oxidative stress produced by frying and led to a higher degree of lipid peroxidation in liver microsomes in vivo than virgin olive oil.
\end{abstract}

Virgin olive oil: Sunflower oil: Fried oil: Lipid peroxidation: Rat

Fats and oils are heated at high temperatures during baking, grilling and pan-frying; deep-fat frying is the most common method of high-temperature treatment (Warner, 1999). Deep-fat frying is a popular food preparation method because it produces desirable fried food flavour, golden-brown colour and crisp texture. Frying has little or no impact on the protein or mineral content of food, whereas thermal stressing of polyunsaturated fatty acid (PUFA)-rich culinary oils according to routine frying or cooking practices generates high levels of cytotoxic aldehydic products, arising from the fragmentation of conjugated hydroperoxydiene precursors. Several compounds produced from the thermally induced autoxidation of PUFA are readily absorbed from the gut into the systemic circulation in vivo (Grootveld et al. 1998). Since such aldehydic products are damaging to human health, it has been indicated that the dietary ingestion of thermally, autoxidatively stressed PUFA-rich culinary oils promotes the induction, development, and progression of cardiovascular diseases (Grootveld et al. 1998).
The high temperature and short transit time of the frying process causes less loss of heat-labile vitamins than other types of cooking. For example, the vitamin $\mathrm{C}$ concentration of French fried potatoes is as high as in raw potatoes, and thiamin is well retained in fried potato products as well as in fried pork meat (Fillion \& Henry, 1998). Although some unsaturated fatty acids and antioxidant vitamins are lost due to oxidation, fried foods are generally a good source of vitamin E (Fillion \& Henry, 1998). Because of high consumption of frying oils and fats, the effect of high temperatures on these oils and fats is of major concern both for product quality and nutrition (Paul \& Mittal, 1997; Fillion \& Henry, 1998; Warner, 1999).

It is well known that dietary fat sources strongly influence several biochemical variables both in plasma and in biological membranes (Mataix et al. 1998; Quiles et al. 1999a; Ramírez-Tortosa et al. 1999). Virgin olive oil has been shown to modulate the damage caused by endogenous and exogenous oxidative stress (Ramírez-Tortosa et al. 1998; Quiles et al. 1999a; Svegliati Baroni et al. 1999).

\footnotetext{
Abbreviation: PUFA, polyunsaturated fatty acid.

* Corresponding author: Dr José L. Quiles, fax +34 958248 326, email jlquiles@ugr.es
} 
Adaptations of microsomes in relation to dietary fat type have been reported (Huertas et al. 1991a,b; Quiles et al. 1999b). The importance of fatty acids resides in the finding that biological membranes adapt their composition according to that of dietary fat (Yamaoka et al. 1988; Charnock et al. 1992; McMillin et al. 1992; Barzanti et al. 1994; Stillwell et al. 1997; Quiles et al. 1999c). Virgin olive oil is particularly rich in antioxidant molecules and it is, together with sunflower oil, one of the most frequently used fat sources in Europe. These two edible oils compete in the market and it is important that physicians and consumers possess more information about the influence that these oils may have on human health.

In light of the previous studies we investigated the effects of dietary fried virgin olive and sunflower oils with regard to the corresponding non-fried ones on the composition of rat liver microsomes. In addition, plasma antioxidants were investigated, as well as the oxidative modifications to virgin olive and sunflower oils that occurred during the frying process.

\section{Materials and methods}

\section{Frying procedure}

Two domestic deep-fat fryers with 3.5 litre A vessels $(260 \times 192 \times 348 \mathrm{~mm})$ were used for frying. The fryers were filled with 3 litres virgin olive or sunflower oil and heated at $180^{\circ} \mathrm{C}$ for $15 \mathrm{~min}$. Four cycles of $15 \mathrm{~min}$ frying were used with $2 \mathrm{~h}$ rest periods between each frying cycle. For the analytical determinations of the oils, samples were preserved after each frying cycle $(15,30,45$ and $60 \mathrm{~min}$ fried oils) and a sample from the non-fried oil was also retained. Frying procedures were repeated with six samples for each oil type. For the animal study, the diet was made using non-fried oil for the non-fried diet groups and oil fried for four cycles of $15 \mathrm{~min}$ (60 min fried oils) for the fried-oil dietary groups. All the oil samples were filtered and stored in a freezer at $-20^{\circ} \mathrm{C}$ before analysis. Table 1 shows the lipid profile of the edible oils used for the frying procedure.

All chemicals and solvents of highest grade available were acquired from Sigma (St Louis, MO, USA) and Merck (Darmstadt, Germany).

\section{Analytical determinations in the oil samples}

Extra virgin olive oil (European Economic Community, 1991) and sunflower oil were purchased in a local supermarket. The fatty acid profile of oil samples was measured by GLC as described by Lepage \& Roy (1986). A portion of each sample $(50 \mu \mathrm{l})$ was weighed precisely into a glass tube and dissolved in $2 \mathrm{ml}$ methanol-benzene $(4: 1, \mathrm{v} / \mathrm{v})$; $50 \mu \mathrm{g}$ fatty acid 13:0 and $9 \mu \mathrm{M}$-butylated hydroxytoluene were added to the samples as internal standard and antioxidant respectively. Acetyl chloride $(200 \mu \mathrm{l})$ was slowly added, then tubes were closed and subjected to methanolysis at $100^{\circ} \mathrm{C}$ for $1 \mathrm{~h}$. After the tubes were cooled in water, $5 \mathrm{ml} 0.43 \mathrm{M}-\mathrm{K}_{2} \mathrm{CO}_{3}$ solution was slowly added to stop the reaction and neutralize the mixture. The tubes were then shaken and centrifuged, the benzene upper
Table 1. Fatty acid composition ( $\mathrm{g} / 100 \mathrm{~g}$ oil) of the non-fried experimental oils†

(Mean values with their standard errors for six oil samples)

\begin{tabular}{|c|c|c|c|c|}
\hline \multirow[b]{2}{*}{ Fatty acid } & \multicolumn{2}{|c|}{ Virgin olive oil } & \multicolumn{2}{|c|}{ Sunflower oil } \\
\hline & Mean & SE & Mean & $\overline{\mathrm{SE}}$ \\
\hline $16: 0$ & $9 \cdot 8^{*}$ & 0.04 & $6 \cdot 3$ & 0.01 \\
\hline $16: 1 n-7$ & $0.6^{*}$ & 0.01 & 0.1 & 0.01 \\
\hline $18: 0$ & 3.9 & 0.02 & 4.4 & 0.01 \\
\hline $18: 1 n-9$ & $76 \cdot 7^{\star}$ & 0.05 & 31.2 & 0.04 \\
\hline $18: 2 n-6$ & $6 \cdot 8^{*}$ & 0.01 & $55 \cdot 9$ & 0.03 \\
\hline $18: 3 n-3$ & $1 \cdot 1^{*}$ & 0.01 & 0.4 & 0.01 \\
\hline $20: 1 n-9$ & $0.3^{*}$ & 0.01 & 0.2 & 0.01 \\
\hline $20: 2 n-6$ & $0.2^{*}$ & 0.02 & 0.1 & 0.01 \\
\hline $20: 4 n-6$ & $0 \cdot 1^{*}$ & 0.01 & 0.7 & 0.01 \\
\hline $20: 5 n-3$ & 0.1 & 0.01 & 0.1 & 0.01 \\
\hline $22: 4 n-6$ & $0 \cdot 1^{*}$ & 0.01 & 0.3 & 0.01 \\
\hline $24: 0$ & 0.1 & 0.02 & 0.1 & 0.02 \\
\hline
\end{tabular}

Mean values were significantly different from those of sunflower oil: ${ }^{\star} P<0.05$. †For details of analytical procedures, see p. 58.

phase was removed and transferred to another glass tube to be dried under $\mathrm{N}_{2}$ and resuspended to a volume of $100 \mu l$ hexane. A GLC Model HP-5890 Series II (Hewlett Packard, Palo Alto, CA, USA) equipped with a flame ionization detector was used to analyse fatty acids as methyl esters. Chromatography was performed using a $60 \mathrm{~m}$ long capillary column, $32 \mathrm{~mm}$ i.d. and $20 \mathrm{~mm}$ thickness, impregnated with Sp $2330^{\mathrm{TM}}$ FS (Supelco Inc., Bellefonte, CA, USA). The injector and the detector were maintained at 250 and $275^{\circ} \mathrm{C}$ respectively; $\mathrm{N}_{2}$ was used as carrier gas and the split ratio was 29:1. Temperature programming (for a total time of $40 \mathrm{~min}$ ) was as follows: initial temperature $160^{\circ} \mathrm{C}$ for $5 \mathrm{~min}, 6^{\circ} \mathrm{C} / \mathrm{min}$ to $195^{\circ} \mathrm{C}, 4^{\circ} \mathrm{C} / \mathrm{min}$ to $220^{\circ} \mathrm{C}$, $2^{\circ} \mathrm{C} / \mathrm{min}$ to $230^{\circ} \mathrm{C}$, hold $12 \mathrm{~min}, 14^{\circ} \mathrm{C} / \mathrm{min}$ to $160^{\circ} \mathrm{C}$.

The concentration of $\alpha$-tocopherol in the oil samples was determined by HPLC with a Beckman in-line Diode Array Detector, model 168 (Fullerton, CA, USA), a Water (Milford, MA, USA) 717 plus auto sampler and a Beckman Ultrasphere $5 \mu \mathrm{m}$ silica column $(250 \mathrm{~mm} \times 4.6 \mathrm{~mm})$. The absorbance of the eluates was monitored at $292 \mathrm{~nm}$. The flow rate was $2 \mathrm{ml} / \mathrm{min}$ and the eluent was methanolwater $(99: 1, \mathrm{v} / \mathrm{v})$. Samples were treated according to Ueda \& Igarashi (1990). Tocopherol peaks were identified by predetermining the retention times of individual tocopherol standards and results expressed as tocopherol equivalents.

Total phenolics were extracted from the oils according to the method described by Vázquez-Roncero et al. (1973). The concentration of total phenols was estimated with the Folin-Ciocalteau reagent using caffeic acid as standard. Total polar components were determined according to Dobarganes et al. (1984).

\section{Analytical determinations in rats}

Thirty-two male Wistar rats (Ratus novergicus) initially weighing 80 to $90 \mathrm{~g}$ (supplied by the Laboratory Animal Service of the University of Granada) were allocated to four groups of eight per cage and maintained on a $12 \mathrm{~h}$ light-dark cycle with free access to food and drinking water. The present study lasted 8 weeks during which the 
rats were fed on semisynthetic and isoenergetic diets with the following composition $(\mathrm{g} / \mathrm{kg}$ diet): casein $267 \cdot 0$, starch $135 \cdot 3$, sucrose $452 \cdot 9$, edible oil $80 \cdot 0$, mineral supplement $36 \cdot 8$, vitamin supplement $10 \cdot 0$, cellulose $18 \cdot 4$, choline 0.9 , methionine 3.0. Mineral and vitamin supplements were designed according to the AIN-76 criteria (American Institute of Nutrition, 1977). Groups only differed in the type of edible oil used for their diet. One group was fed on nonfried virgin olive oil, another group was fed on fried virgin olive oil, the third group was fed on non-fried sunflower oil and the fourth group was fed on fried sunflower oil. The fried oils used for the animal experiment were $60 \mathrm{~min}$ fried oils according to the procedure described earlier.

At the end of the experiment, the rats were killed by decapitation at the same time of the day (between 12.00 and 13.00 hours) to avoid circadian fluctuations. The protocols were approved by the Ethical Committee of the Interministerial Commission of Science and Technology. Animals were handled according to the guidelines for care and use of laboratory animals of the Spanish Society for Laboratory Animal Sciences.

Blood was collected in EDTA-coated tubes, and plasma obtained by centrifugation at $1750 \mathrm{~g}$ for $10 \mathrm{~min}$. All samples were stored at $-80^{\circ} \mathrm{C}$ until analysis. Liver microsomal membranes were isolated following Fleischer et al. (1979) as previously described (Huertas et al. 1991a). The protein concentrations of microsomal samples were determined according to the method of Lowry et al. (1951), using bovine serum albumin as a standard.

The fatty acid profile of liver microsomes was measured by GLC as described by Lepage \& Roy (1986) for the oil samples.

The ferrous oxide-xylenol orange method was used for determining hydroperoxides. Hydroperoxide levels in rat liver microsomes were assayed according to the principle of the rapid peroxide-mediated oxidation of $\mathrm{Fe}^{2+}$ to $\mathrm{Fe}^{3+}$ under acidic conditions (Nourooz-Zadeh et al. 1994) using triphenylphosphine, an agent that avoids artifactual colour generation in samples, which might contain substantial quantities of loosely available Fe. Briefly, microsomes $(0.1 \mathrm{mg})$ were incubated at $37^{\circ} \mathrm{C}$ for $30 \mathrm{~min}$ with and without $1 \mathrm{~mm}$-triphenylphosphine. Ferrous oxide-xylenol orange reagent was added to each sample and incubated again at $37^{\circ} \mathrm{C}$ for $30 \mathrm{~min}$ in a shaking water-bath. After centrifugation ( $2000 \mathrm{~g}$ for $5 \mathrm{~min}$ ) the absorbance of the supernatant fractions was monitored at $560 \mathrm{~nm}$. Lipid hydroperoxides were measured as baseline levels and after an induction with 2,2'-azobis (2-aminidinopropane) dihydrocloride. Microsomal thiobarbituric acid-reactive substances were determined according to Orrenius et al. (1977).

Analyses of ubiquinone 9 and $\alpha$-tocopherol in microsomes were carried out according to Lang \& Packer (1987), by HPLC with in-line Diode Array Detector, model 168 (Beckman Instruments, Inc.). Plasma ubiquinone 9 and $\alpha$-tocopherol were assayed by the same HPLC apparatus described earlier according to MacCrehan (1990).

\section{Statistical analysis}

Each value obtained is the mean with its standard error of six samples for oils or eight samples for rats. Differences among periods of time were analysed by one-way ANOVA. All variables were tested for normality and homogeneous variance by Levene test. When a variable was found not to be normally distributed it was log-transformed before analysis. Duncan's test was performed post hoc to evaluate differences among groups. $P<0.05$ was considered significant. Data were analysed using SPSS statistical software package (SPSS for Windows, 9.0.1; SPSS Inc. Chicago, IL, USA).

\section{Results and discussion}

It is very important to assess the oxidative degradation of fats and oils, because free-radical initiated oxidation is one of the main causes of rancidity in fats and oils, which results in the alteration of major quality control variables such as colour, flavour, aroma and nutritional value (Donelly \& Robinson, 1995).

Oxidative injury is assumed to play a crucial role in the development of several chronic diseases, including CHD and cancer (Halliwell \& Gutteridge, 1999). Dietary fatty acids can influence the susceptibility of cells to oxidative stress, perhaps due to changes in cell membrane fatty acid composition (Battino et al. 1999). Moreover, since some aldehydic products are damaging to human health (Grootveld et al. 1998), the ingestion of thermally stressed PUFA-rich culinary oils may promote some pathologies.

Concerning the effect of frying on the alterations produced to the experimental oils in the present study, Table 2 shows the proportion of total PUFA, and the contents in $\alpha$-tocopherol, total phenolics and total polar materials present in the oils. Non-fried oils showed a typical PUFA profile (Gunstone et al. 1994), with much higher levels in sunflower oil compared with virgin olive oil. We did not find changes in PUFA content after frying (Table 2). These results agree with the proposed model of a shorttime, low-impact frying procedure, in which large changes in the lipid profile, typical of deeply over-fried oils (where multiple hydrolysis, cyclation and oxidation reactions take place) were avoided. In the present study, we focused on changes in the antioxidant content of the oils induced by frying.

Sunflower oil had a higher content of $\alpha$-tocopherol than virgin olive oil (Table 2 ). These values significantly decreased in both oils after $60 \mathrm{~min}$ of frying. However, the response was different depending on the oil. Sunflower oil lost 201.2 and virgin olive oil $127.03 \mathrm{mg} \alpha$-tocopherol/ $\mathrm{kg}$. These losses of tocopherol are in agreement with other studies (Barrera-Arellano et al. 1997) and suggest that vitamin $\mathrm{E}$ is being used to protect the oils against the thermal damage.

It was not possible to detect total phenolic compounds in sunflower oil. For virgin olive oil, $150 \mathrm{mg}$ was determined for the non-fried oil (Table 2). The frying procedure reduced the content of phenolics in virgin olive oil after each frying cycle until a final reduction, after $60 \mathrm{~min}$ frying, to about $50 \%$ of the initial value. Phenolic compounds are part of the unsaponifiable fraction of virgin olive oil; they have a great importance for flavour, shelflife and resistance against oxidation (Gutfinger, 1981; 
Table 2. Effect of frying on the proportion of polyunsaturated fatty acids, the content of $\alpha$-tocopherol, total phenolics and total polar components in virgin olive oil and sunflower oilq

(Mean values with their standard errors for six oil samples)

\begin{tabular}{|c|c|c|c|c|c|c|c|c|c|}
\hline \multirow[b]{2}{*}{ Edible oil } & \multirow[b]{2}{*}{ Frying time (min) } & \multicolumn{2}{|c|}{ PUFA (g/100 g) } & \multicolumn{2}{|c|}{$\alpha$-Tocopherol (mg/kg) } & \multicolumn{2}{|c|}{$\begin{array}{l}\text { Total phenolics } \\
(\mathrm{mg} / \mathrm{kg})\end{array}$} & \multicolumn{2}{|c|}{$\begin{array}{l}\text { Total polar } \\
\text { components } \\
(\mathrm{g} / 100 \mathrm{~g})\end{array}$} \\
\hline & & Mean & SE & Mean & SE & Mean & SE & Mean & SE \\
\hline \multirow[t]{5}{*}{ Virgin olive } & 0 & $8 \cdot 3^{*}$ & 0.1 & $388.9^{*}$ & $9 \cdot 2$ & $150 \cdot 1^{*}$ & $5 \cdot 9$ & $3.5^{\star}$ & 0.1 \\
\hline & 15 & $8 \cdot 3^{*}$ & 0.2 & $388.9^{*}$ & 13.4 & $121.4^{*} \dagger$ & $3 \cdot 7$ & $3 \cdot 6^{*}$ & 0.1 \\
\hline & 30 & $8 \cdot 3^{*}$ & 0.1 & $375 \cdot 4^{*}$ & $13 \cdot 8$ & $118 \cdot 9^{*} \dagger$ & $4 \cdot 8$ & $3 \cdot 7^{\star}$ & 0.1 \\
\hline & 45 & $8 \cdot 4^{*}$ & $0 \cdot 1$ & $365 \cdot 9^{*} \dagger \ddagger \S$ & $16 \cdot 1$ & $87 \cdot 6^{\star} \dagger \neq \S$ & $1 \cdot 1$ & $4 \cdot 4^{*} \dagger \ddagger \S$ & 0.1 \\
\hline & 60 & $8 \cdot 3^{*}$ & 0.1 & $276 \cdot 9^{\star} \dagger ‡ \S$ & $50 \cdot 7$ & $73 \cdot 4^{*} † \ddagger \S \|$ & 3.5 & $4 \cdot 6^{\star} \dagger \neq \S$ & 0.2 \\
\hline \multirow[t]{5}{*}{ Sunflower } & 0 & 57.8 & 0.1 & $1421 \cdot 1$ & 41.9 & ND & & 4.8 & 0.12 \\
\hline & 15 & $57 \cdot 4$ & 0.2 & $1256 \cdot 8 \dagger$ & $28 \cdot 1$ & ND & & $5.8 \dagger$ & 0.2 \\
\hline & 30 & $57 \cdot 1$ & 0.2 & $1279 \cdot 1 \dagger$ & $15 \cdot 3$ & ND & & $6 \cdot 1 \dagger$ & 0.1 \\
\hline & 45 & $56 \cdot 9$ & 0.5 & $1257.9 \dagger$ & $20 \cdot 2$ & ND & & $6.4 \dagger$ & 0.1 \\
\hline & 60 & $57 \cdot 7$ & 0.4 & $1219 \cdot 9 \dagger$ & $19 \cdot 3$ & ND & & $7 \cdot 1 \dagger \ddagger \S \|$ & 0.3 \\
\hline
\end{tabular}

PUFA, polyunsaturated fatty acids; ND, not detected.

Mean values were significantly different from those of sunflower oil for the same frying time: ${ }^{*} P<0.05$.

Mean values were significantly different from those at $0 \mathrm{~min}$ for the same oil: $\dagger P<0.05$.

Mean values were significantly different from those at $15 \mathrm{~min}$ for the same oil: $\ddagger P<0.05$.

Mean values were significantly different from those at $30 \mathrm{~min}$ for the same oil: $\S P<0.05$.

Mean values were significantly different from those at $45 \mathrm{~min}$ for the same oil: $\| P<0.05$.

I For details of oils and procedures, see Table 1 and p. 58.

Tsimidou et al. 1996) and they are very liable to being lost over time as a consequence of hydrolytic or oxidative processes during storage (Cortesi et al. 1995; Cinquanta et al. 1997). Their concentrations in oils differ widely depending on the variety, location, maturity and other factors (Amiot et al. 1986; Cinquanta et al. 1997). The frying procedure probably reduced the content of phenolics as a result of thermal destruction or because of their use in the protection of the oils against the oxidative insult.

Total polar components represent a good marker of the total alteration of the oil and in fried oils are the breakdown products due to the frying process (Melton et al. 1994). Total polar components increased in both experimental groups after frying (Table 2). The highest value and increment for each frying time were found in sunflower oil; this effect is common in very unsaturated oils (Takeoka et al. 1997).

It is possible to conclude that frying virgin olive and sunflower oils affected the antioxidant content of both oils and induced the appearance of toxic compounds but in a different way depending on the oil. Thus, although both oils lost tocopherol after frying, the loss from sunflower oil started after $15 \mathrm{~min}$ and for virgin olive oil after $45 \mathrm{~min}$ of frying. This difference, together with the fact that sunflower oil lost, in absolute terms, a higher amount of $\alpha$-tocopherol, may be important since it suggests that virgin olive oil resisted the frying procedure better. This is consistent with its lower level of total polar material. Such results lead us to hypothesize that the intake of these fried oils could differentially affect several aspects of metabolism. Thus, we fed rats for 8 weeks with the non-fried or the $60 \mathrm{~min}$ fried oils to study oxidative stress in liver microsomes.

Dietary intake did not change significantly among the groups. Body weight was similar for all the groups throughout the present study and the weight of the liver was not affected by the experimental treatments (results not shown). Fig. 1 shows the proportion of different fatty acid fractions in microsomal membranes of the rats. The type of oil or the thermal treatment did not affect the proportions of total saturated fatty acids (calculated by summation of the following fatty acids: 12:0, 14:0, 16:0, 18:0, 20:0 and 22:0) in rat microsomes (Fig. 1(A)), which is in accordance with studies describing that this is a very stable fraction of fatty acids (Quiles et al. 1999a). Animals fed on non-fried or fried virgin olive oil had a higher proportion of total monounsaturated fatty acids (calculated by summation of the following fatty acids: 16:1 n-7, 18:1 n-7, 16:1 n-9, 18:1 n-9 and 24:1 n-9) (Fig. 1(B)). Frying did not affect virgin olive oil-fed animals but decreased the level of monounsaturated fatty acids in sunflower oil-fed animals. Animals fed on sunflower oil reached the highest values of $n$-6 PUFA (calculated by summation of the following fatty acids: 18:2 $n-6$, 20:2 n-6, 20:3 n-6, 20:4 n-6 and 22:4 n-6) (Fig. 1(C)). Frying only affected sunflower oil-fed rats with an increase in this fatty acid fraction. Frying did not change the proportion of $n$-3 PUFA (calculated by summation of the following fatty acids: 20:5 n-3, 22:5 n-3, 22:6 n-3), but animals fed on virgin olive oil had a higher amount than those fed sunflower oil (Fig. 1(D)).

Fig. 2 shows the levels of thiobarbituric acid-reactive substances and hydroperoxides in rat liver microsomes. Animals fed on the non-fried virgin olive oil showed lower levels of thiobarbituric acid-reactive substances than those fed non-fried sunflower oil (Fig. 2(A)). Feeding fried oil led to higher levels of thiobarbituric acid-reactive substances in both groups although sunflower oil-fed animals reached the highest value. In regard to baseline hydroperoxides (Fig. 2(B)), fried oils led to microsomes with a higher content of these compounds than non-fried oils. For 2,2'-azobis (2-aminidinopropane) dihydroclorideinduced hydroperoxides (Fig. 2(C)), no differences were found between animals fed on the non-fried oils and a 

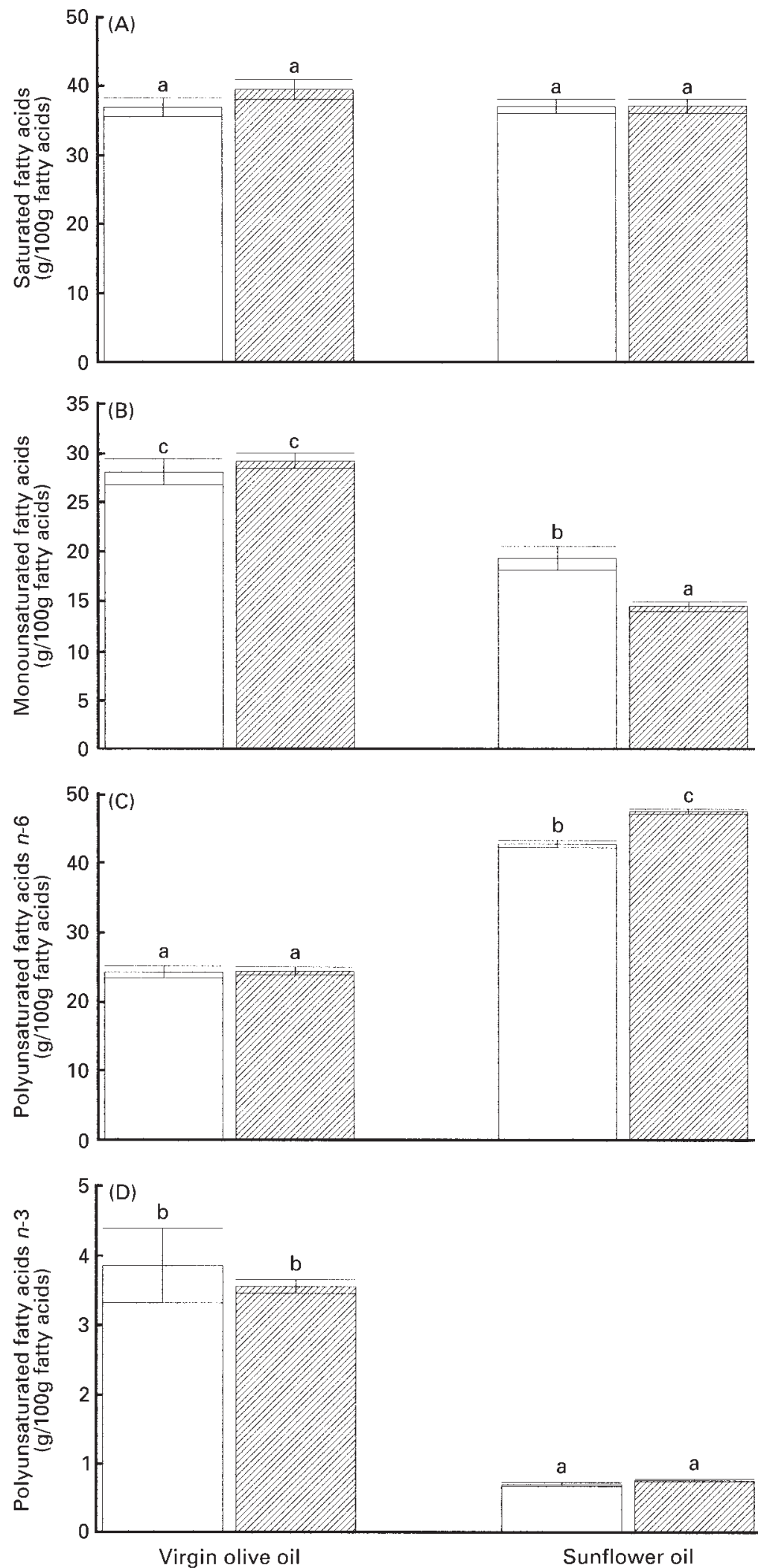

Fig. 1. Effect of feeding virgin olive or sunflower fried oils for 8 weeks on the proportion of: (A), saturated fatty acids; (B), monounsaturated fatty acids; (C), polyunsaturated $n-6$ fatty acids; (D), polyunsaturated $n-3$ fatty acids in rat liver microsomes. $\square$, Non-fried oil; $\mathbb{2}$, fried oil. For details of oils, diets and procedures, see Tables 1 and 2 and p. 58. Values are means for eight animals with standard errors shown by vertical bars. ${ }^{a, b, c}$ Mean values with unlike superscript letters were significantly different $(P<0.05)$. 

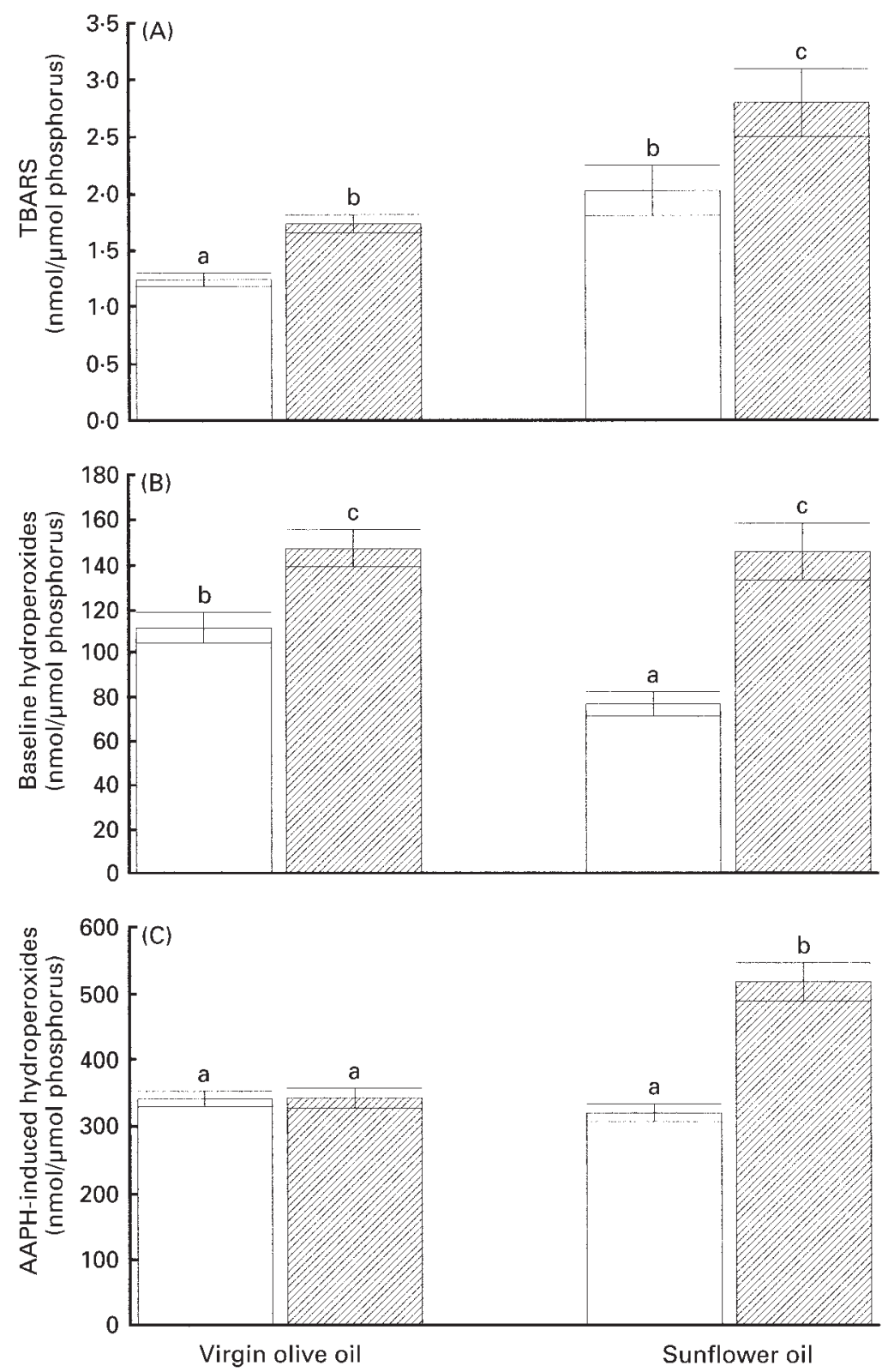

Fig. 2. Effect of feeding virgin olive or sunflower fried oils for 8 weeks on the production of: (A), thiobarbituric acid-reactive substances (TBARS); $(B)$, baseline hydroperoxides; (C), 2,2'-azobis (2-aminidinopropane) dihydrocloride (AAPH)induced hydroperoxides in rat liver microsomes. $\square$, Non-fried oil; $\mathbb{Z}$, fried oil. For details of oils, diets and procedures, see Tables 1 and 2 and p. 58. Values are means for eight animals with standard errors shown by vertical bars. ${ }^{\mathrm{a}, \mathrm{b}, \mathrm{c}}$ Mean values with unlike superscript letters were significantly different $(P<0.05)$.

higher level in rats fed the fried sunflower oil was observed.

The effects that feeding different fat sources with different unsaturation degrees have on lipid peroxidation have been well described in the past years. These studies led to the conclusion that highly unsaturated fats are prone to induce membrane lipid peroxidation (Huertas et al. 1991a,b; Ramírez-Tortosa et al. 1997; Mataix et al. 1998; Quiles et al. 1999c), as observed in the present study for sunflower oil-rich diets. In addition, the results from lipid peroxidation measurements confirm that the loss of antioxidants and the increase in toxic compounds in fried oils affected microsomal membranes, suggesting that feeding fried foods may represent a direct source of oxidative stress for the organism. In that sense, Liu \& Huang (1995) described an increase in tissue thiobarbituric acid-reactive substances in rats fed on oxidized fried oil compared with control rats.

In relation to microsomal lipid peroxidation, the pro-oxidant effect of frying could arise from alterations in the lipid profile of microsomal membranes or be due to the antioxidant content of the animals. Animals fed on fried 
sunflower oil showed a higher proportion of $n-6$ PUFA and a lower proportion of monounsaturated fatty acids than animals fed on the non-fried sunflower oil. These modifications may be sufficient to induce lipid peroxidation. Moreover, differences in antioxidant concentrations were also found. In plasma, $\alpha$-tocopherol and ubiquinone concentrations were lower in rats fed on the two fried oils, with no differences between oil types (Fig. 3). These lower levels of plasma antioxidants confirm that a condition of stress occurred in these animals. In that sense, it has been previously described (Quiles et al. 1999b,c) that during oxidative insults, ubiquinone and $\alpha$-tocopherol are mobilized from the plasma compartment (which would behave as an antioxidant 'reservoir') towards the sites that need additional antioxidant. In the present study, such a hypothesis is supported by the lower levels of both antioxidants found in plasma after fried oil dietary administration.

However, the results on microsomal antioxidant concentrations (Fig. 4) were not as clear as those found in plasma for the effect of frying, although for non-fried oils there were no differences. There was a lower level of microsomal $\alpha$-tocopherol in fried virgin olive oil-fed animals compared with the non-fried oil groups, but there was no difference between rats fed non-fried sunflower oil. For microsomal ubiquinone 9 (Fig. 4(B)), similar values were detected for animals fed on the non-fried oils. No changes were observed after feeding fried sunflower oil, but fried virgin olive oil led to animals with a higher concentration of microsomal ubiquinone 9. The lack of a significant effect of fried sunflower oil for $\alpha$-tocopherol and ubiquinone might be due to too small sample size. As far as we know, no studies have been conducted concerning ubiquinone levels and the intake of fried oils. In relation to $\alpha-$ tocopherol, a decrease in several tissues has been described in rats fed on diets based on a fried soyabean oil $(150 \mathrm{~g} / \mathrm{kg}$ diet) (Liu \& Huang, 1996) suggesting that fried oil intake leads to a higher tocopherol catabolism or turnover in rats. In the present study, only animals fed on fried virgin olive oil showed such decrease but these animals showed a higher level of ubiquinone 9 and the lowest degree of lipid peroxidation. Nevertheless, the lower level of plasma antioxidants found here agrees with the idea of an increased antioxidant turnover induced by the fried oils.

In conclusion, fried edible oils fed to rats for 8 weeks induced lipid peroxidation in liver microsomes compared with the same non-fried oils. It seems that a strong relationship exists between the loss of antioxidants and the production of toxic compounds in the oils after frying and the extent of the peroxidative events in microsomes, which was also different depending on the fat source. Thus, we found that the highly unsaturated sunflower oil
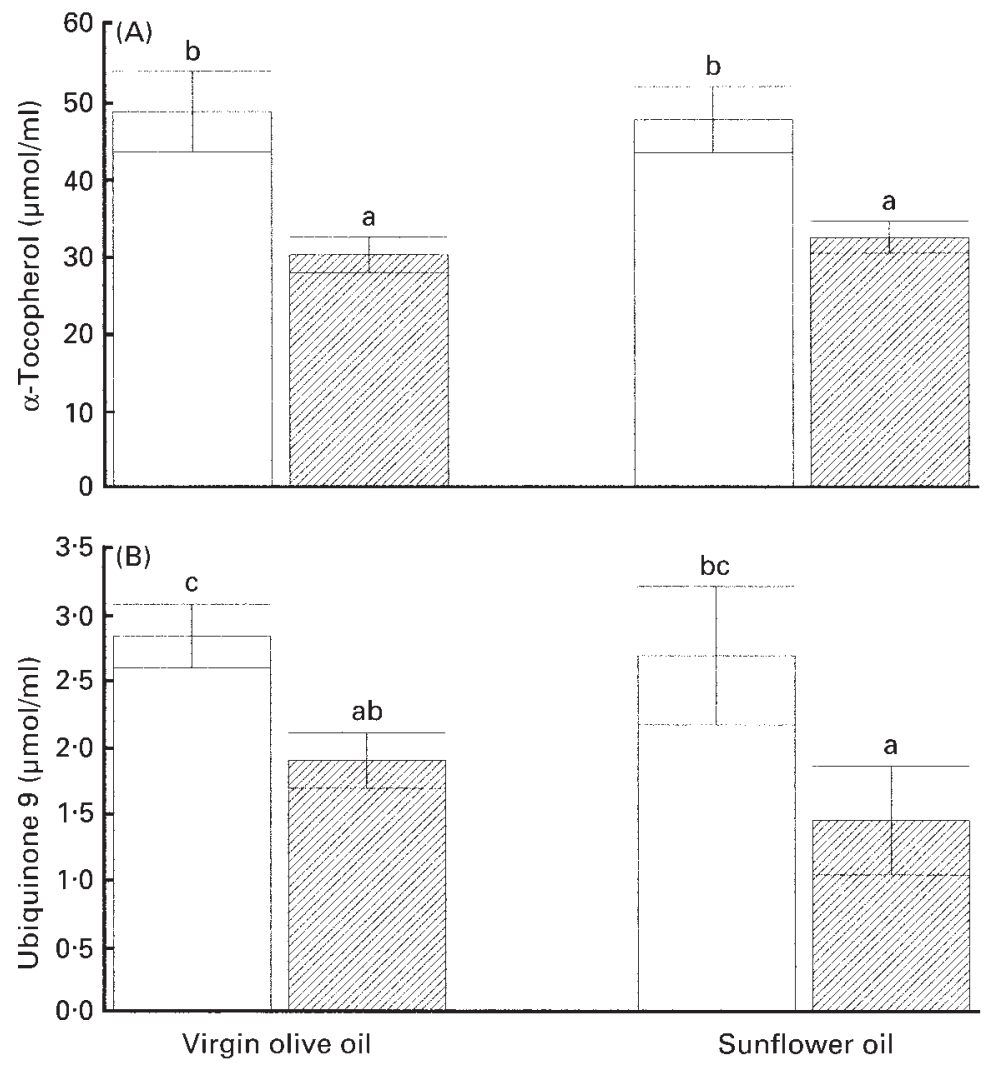

Fig. 3. Effect of feeding virgin olive or sunflower fried oils for 8 weeks on the plasma content of: (A), $\alpha$-tocopherol; (B), ubiquinone 9 in rats. $\square$, Non-fried oil; 四, fried oil. For details of oils, diets and procedures, see Tables 1 and 2 and p. 58. Values are means for eight animals with standard errors shown by vertical bars. ${ }^{a, b, c}$ Mean values with superscript letters were significantly different $(P<0.05)$. 

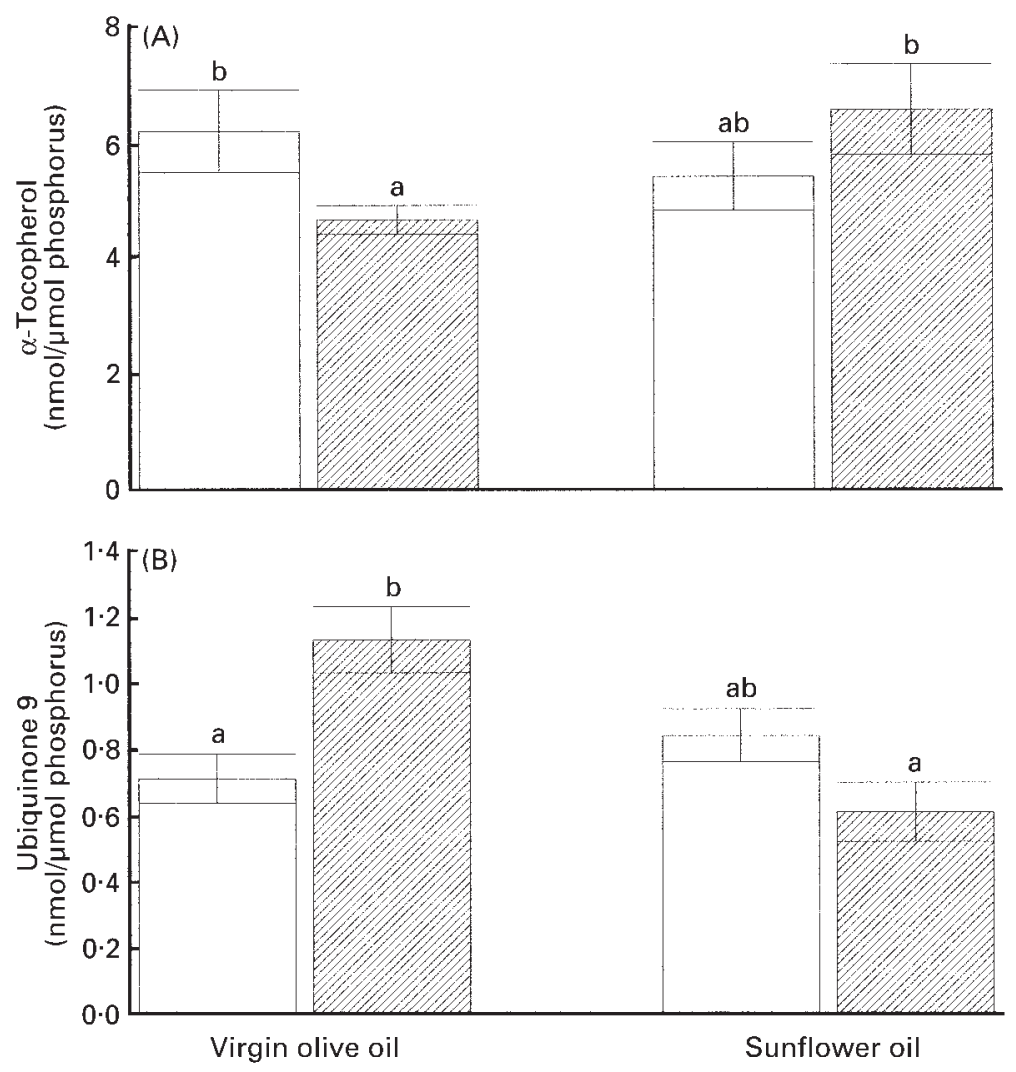

Fig. 4. Effect of feeding virgin olive or sunflower fried oils for 8 weeks on the content of: (A), $\alpha$-tocopherol; (B), ubiquinone 9 in rat liver microsomes. $\square$, Non-fried oil; 尼, fried oil. For details of oils, diets and procedures, see Tables 1 and 2 and p. 58. Values are means for eight animals with standard errors shown by vertical bars. ${ }^{a, b}$ Mean values with superscript letters were significantly different $(P<0.05)$.

resisted to a lower extent the stress produced by the frying and led to a higher degree of lipid peroxidation in liver microsomes than virgin olive oil. Apparently, the changes produced in microsomal lipid profile together with alterations in the levels of antioxidants defined the extent of peroxidation.

\section{Acknowledgements}

This work was supported by CICYT project ALI91-1113C03-01. M. Battino was a visiting scientist at Granada University, thanks to Ministerio de Educación y Ciencia, Madrid. J.L. Quiles and M.C. Ramirez-Tortosa received a short-term fellowship by Ancona University.

\section{References}

American Institute of Nutrition (1977) Report of the American Institute of Nutrition ad hoc committee on standards for nutritional studies. Journal of Nutrition 107, 1340-1348.

Amiot MT, Fleuriet A \& Macheix JT (1986) Importance and evolution of phenolic compounds in olive during growth and maturation. Journal of Agricultural and Food Chemistry 34, $823-826$
Barrera-Arellano D, Marquez-Ruiz G \& Dobarganes MC (1997) A simple procedure to evaluate the performance of fats and oils at frying temperatures. Grasas y Aceites 48, 231-235.

Barzanti V, Battino M, Baracca A, Cavazzoni M, Cocchi M, Noble R, Maranesi M, Turchetto E \& Lenaz G (1994) The effect of dietary lipid changes on the fatty acid composition and function of liver, heart and brain mitochondria in the rat at different ages. British Journal of Nutrition 71, 193-202.

Battino M, Bullon P, Wilson M \& Newman H (1999) Oxidative injury and inflammatory periodontal diseases: the challenge of anti-oxidants to free radicals and reactive oxygen species. Critical Reviews in Oral Biology and Medicine 10, 458-476.

Charnock JS, McLennan PL \& Abeywardena MY (1992) Dietary modulation of lipid metabolism and mechanical performance of the heart. Molecular and Cellular Biochemistry 116, 19-25.

Cinquanta L, Esti M \& La Notte E (1997) Evolution of phenolic compounds in virgin olive oil during storage. Journal of the American Oil Chemists' Society 74, 1259-1264.

Cortesi N, Azzolini M, Rovellini P \& Fedeli E (1995) I componenti minori polari degli oli vergini di oliva: ipotesi di structuttura mediante LC-MS (Minor polar components from virgin olive oil: hypothesis of structure by LC-MS). Rivista Italiana di Sostanze Grasse 43, 1802-1807.

Dobarganes MC, Pérez MC \& Gutiérrez R (1984) Métodos analíticos de aplicación en grasas calentadas. I. Determinación de ésteres metílicos no alterados (Analytical methods for application on heated fats. I. Determination of non modified methyl esters). Grasas y Aceites 35, 172-177. 
Donelly JK \& Robinson DS (1995) Free radicals in foods. Free Radical Research 22, 147-176.

European Economic Community (1991) On the characteristics of olive oil and olive-residue oil and on the relevant methods of analysis. Diario Oficial de las Communidades Europeas L248, 1-82.

Fillion L \& Henry CJ (1998) Nutrient losses and gains during frying: a review. International Journal of Food Sciences and Nutrition 49, 157-168.

Fleischer S, McIntyre IO \& Vidal JC (1979) Large scale preparation of rat liver mitochondria in high yield. Methods in Enzymology 55, 32-39.

Grootveld M, Atherton MD, Sheerin AN, Haweks J, Blake DR, Richens TE, Silwood CJL, Lynch E \& Claxon AWD (1998) In vivo absorption, metabolism, and urinary excretion of alpha,beta-unsaturated aldehydes in experimental animals. Relevance to the development of cardiovascular diseases by the dietary ingestion of thermally stressed polyunsaturate-rich culinary oils. Journal of Clinical Investigation 101, 1210-1218.

Gunstone FD, Harwood JL \& Padley FB (1994) The Lipid Handbook, 2nd ed., pp. 53-117. London: Chapman \& Hall.

Gutfinger T (1981) Polyphenols in olive oils. Journal of the American Oil Chemists' Society 58, 966-968.

Halliwell B \& Gutteridge JMC (1999) Free Radicals in Biology and Medicine. Oxford: Oxford University Press.

Huertas JR, Battino M, Lenaz G \& Mataix J (1991a) Changes in mitochondrial and microsomal rat liver coenzyme $\mathrm{Q}_{9}$ and $\mathrm{Q}_{10}$ content induced by dietary fat and endogenous lipid peroxidation. FEBS Letters 287, 89-92.

Huertas JR, Battino M, Mataix FJ \& Lenaz G (1991b) Cytochrome oxidase induction after oxidative stress induced by adriamycin in liver of rats fed with dietary olive oil. Biochemical and Biophysical Research Communications 181, 375-382.

Lang JK \& Packer L (1987) Quantitative determination of vitamin $\mathrm{E}$ and oxidised and reduced CoQ by high-performance liquid chromatography with in-line ultraviolet and electrochemical detection. Journal of Chromatography 385, 109-117.

Lepage G \& Roy CC (1986) Direct transesterification of all classes of lipids in one-step reaction. Journal of Lipid Research 27, 114-120.

Liu JF \& Huang CJ (1995) Tissue alpha-tocopherol retention in male rats is compromised by feeding diets containing oxidized frying oil. Journal of Nutrition 125, 3071-3080.

Liu JF \& Huang CJ (1996) Dietary oxidized frying oil enhances tissue alpha-tocopherol depletion and radioisotope tracer excretion in vitamin E-deficient rats. Journal of Nutrition 126, 2227-2235.

Lowry OH, Rosebrough NJ, Farr AL \& Randall RG (1951) Protein measurement with the Folin phenol reagent. Journal of Biological Chemistry 193, 265-275.

MacCrehan WA (1990) Determination of retinol, $\alpha$-tocopherol and $\beta$-carotene in serum by liquid chromatography. Methods in Enzymology 189, 172-181.

McMillin JB, Bick RJ \& Benedict CR (1992) Influence of dietary fish oil on mitochondrial function and response to ischemia. American Journal of Physiology 263, H1479-H1485.

Mataix J, Quiles JL, Huertas JR, Battino M \& Mañas M (1998) Tissue specific interactions of exercise, dietary fatty acids, and vitamin $\mathrm{E}$ in lipid peroxidation. Free Radicals in Biology and Medicine 24, 511-521.

Melton SL, Jafar S, Sykes D \& Trigiano MK (1994) Review of stability measurements for frying oils and fried food flavor. Journal of the American Oil Chemists' Society 71, 1301-1308.

Nourooz-Zadeh J, Tajaddini-Sarmadi J \& Wolff S (1994)
Measurement of plasma hydroperoxide concentrations by the ferrous oxidation-xylenol orange assay in conjunction with triphenylphosphine. Analytical Biochemistry 220, 403-409.

Orrenius S, Moldeus P, Theor H \& Hogberg J (1977) Microsomes and Drugs Oxidations. New York, NY: Pergamon.

Paul S \& Mittal GS (1997) Regulating the use of degraded oil/fat in deep-fat/oil food frying. Critical Reviews in Food Science and Nutrition 37, 635-662.

Quiles JL, Huertas JR, Mañas M, Battino M \& Mataix J (1999a) Physical exercise affects the lipid profile of mitochondrial membranes in rats fed with virgin olive oil or sunflower oil. British Journal of Nutrition 81, 21-24.

Quiles JL, Huertas JR, Mañas M, Ochoa JJ, Battino M \& Mataix J $(1999 b)$ Oxidative stress induced by exercise and dietary fat modulates the coenzyme Q and vitamin A balance between plasma and mitochondria. International Journal for Vitamin and Nutrition Research 69, 243-249.

Quiles JL, Ramírez-Tortosa MC, Ibañez S, González A, Duthie GG, Huertas JR \& Mataix J (1999c) Vitamin E supplementation increases the stability and the in vivo antioxidant capacity of refined olive oil. Free Radicals Research 31, $129-135$.

Ramírez-Tortosa MC, Aguilera CM, Quiles JL \& Gil A (1998) Influence of dietary lipids on lipoprotein composition and LDL $\mathrm{Cu}^{2+}$ induced oxidation in rabbits with experimental atherosclerosis. Biofactors 8, 79-85.

Ramírez-Tortosa MC, Gil A, Quiles JL \& Mataix J (1997) Rabbit liver mitochondria coenzyme Q10 and hydroperoxide levels: an experimental model of atherosclerosis. Molecular Aspects of Medicine 18, 233-236.

Ramírez-Tortosa C, Lopez-Pedrosa JM, Suarez A, Ros E, Mataix J \& Gil A (1999) Olive oil- and fish oil-enriched diets modify plasma lipids and susceptibility of LDL to oxidative modification in free-living male patients with peripheral vascular disease: the Spanish Nutrition Study. British Journal of Nutrition 82, $31-39$.

Stillwell W, Jenski LJ, Crump FT \& Ehringer W (1997) Effect of docosahexaenoic acid on mouse mitochondrial membrane properties. Lipids 32, 497-506.

Svegliati-Baroni S, Amelio M, Sangiorgi Z, Gaddi A \& Battino M (1999) Solid monounsaturated diet lowers LDL unsaturation trait and oxidisability in hypercholesterolemic (type IIb) patients. Free Radical Research 30, 275-285.

Takeoka GR, Fuli GH \& Dao LT (1997) Effect of heating on the characteristics and chemical composition of selected frying oils and fats. Journal of Agricultural and Food Chemistry 45, 3244-3249.

Tsimidou M, Lytridou M, Boskou D, Pappa-Louisi A, Kotsifaki F \& Petrakis C (1996) On the determination of minor phenolic acids of virgin olive oil by RP-HPLC. Grasas y Aceites 47, $151-157$.

Ueda T \& Igarashi O (1990) Determination of vitamin E in biological specimens and foods by HPLC. Pretreatment of Samples and extraction of tocopherols. Journal of Micronutrient Analysis 7, 79-96.

Vázquez-Roncero A, Janer del Valle C \& Janer del Valle ML (1973) Determinación de los polifenoles totales del aceite de oliva. Grasas y Aceites 24, 350-355.

Warner K (1999) Impact of high-temperature food processing on fats and oils. Advances in Experimental Medicine and Biology 459, 67-77.

Yamaoka S, Urade R \& Kito M (1988) Mitochondrial function in rats is affected by modification of membrane phospholipids with dietary sardine oil. Journal of Nutrition 118, 290-296. 